\title{
Placental expression of the angiogenic placental growth factor is stimulated by both aldosterone and simulated starvation
}

Nicole Eisele ${ }^{1,2}$, Christiane Albrecht ${ }^{3,4}$, Hiten D. Mistry ${ }^{1,2}$, Bernhard Dick ${ }^{1,2}$, Marc Baumann ${ }^{4,5}$, Daniel Surbek $^{4,5}$, Gemma Currie ${ }^{6}$, Christian Delles ${ }^{6}$, Markus G. Mohaupt ${ }^{1,2 * 8}$, Geneviève Escher ${ }^{1,2 *}$, Carine Gennari-Moser ${ }^{1,2 *}$.

${ }^{1}$ Department of Nephrology, Hypertension and Clinical Pharmacology; ${ }^{2}$ Department of Clinical Research; ${ }^{3}$ Institute for Biochemistry and Molecular Medicine; ${ }^{4}$ Department of Obstetrics and Gynecology, University Hospital Bern; ${ }^{5}$ Swiss National Center of Competence in Research, NCCR TransCure; ${ }^{1-5}$ all University of Bern, 3010 Berne, Switzerland; ${ }^{6}$ Institute of Cardiovascular and Medical Sciences, University of Glasgow, Glasgow, UK.

*shared last authorship, ${ }^{\S}$ corresponding author

Keywords: aldosterone; placental growth factor; pregnancy; glucose; trophoblast

Short Title: Aldosterone and PlGF in pregnancy

Corresponding Author: Markus G. Mohaupt, MD

Division of Hypertension

Department of Nephrology, Hypertension and Clinical Pharmacology University of Bern

CH-3010 Berne, Switzerland

Tel: $\quad$ +41316329731

Fax: $\quad$ +41316329734

Email: markus.mohaupt@insel.ch 


\begin{abstract}
Aldosterone is an important factor supporting placental growth and fetal development. Recently, expression of placental growth factor (PlGF) has been observed in response to aldosterone exposure in different models of atherosclerosis. Thus, we hypothesized that aldosterone up-regulates growth-adaptive angiogenesis in pregnancy, via increased placental PlGF expression.

We followed normotensive pregnant women $(n=24)$ throughout pregnancy and confirmed these results in a second independent first trimester cohort $(n=36)$. Urinary tetrahydroaldosterone was measured by gas chromatography-mass spectrometry and corrected for creatinine. Circulating PIGF concentrations were determined by ELISA. Additionally, cultured cell lines, adrenocortical H295R and choriocarcinoma BeWo cells, as well as primary human third trimester trophoblasts were tested in vitro. PIGF serum concentrations positively correlated with urinary tetrahydroaldosterone corrected for creatinine in these two independent cohorts. This observation was not due to PlGF, which did not induce aldosterone production in cultured H295R cells. On the other hand, PIGF expression was specifically enhanced by aldosterone in the presence of forskolin $(\mathrm{p}<0.01)$ in trophoblasts. A pronounced stimulation of PIGF expression was observed with reduced glucose concentrations simulating starvation $(\mathrm{p}<0.001)$.

In conclusion, aldosterone stimulates placental PIGF production, enhancing its availability during human pregnancy, a response amplified by reduced glucose supply. Given the crucial role of PIGF in maintaining a healthy pregnancy, these data support a key role of aldosterone for a healthy pregnancy outcome.
\end{abstract}




\section{Introduction}

Evidence accumulates for almost every physiological system to be closely embedded and regulated by environmental conditions and factors. In pregnancy, similar to the non-pregnant state, the renin-angiotensin II-aldosterone system is a mechanism closely related to salt and water availability (1). As such, numerous effects beneficial to pregnancy have already been attributed to aldosterone. These include, but are not limited to maternal plasma volume expansion, improved fetal conditions and size, placental growth and lower maternal blood pressure (2-8). We recently described that vascular endothelial growth factor (VEGF) alone and in combination with angiotensin II, directs augmented aldosterone production in pregnancy (9), suggesting a physiological survival benefit.

These advantageous characteristics of aldosterone are in marked contrast to its deleterious effects in the non-pregnant state. Organ fibrosis and atherosclerosis are promoted by excess aldosterone (10). Upon exposure of vessels to aldosterone in models of atherosclerosis, enhanced placental growth factor (PIGF) expression has been observed, mediated by a mineralocorticoid responsive element in the promoter region of $\operatorname{plg} f(10,11)$. In non-pregnant systemic vasculature, aldosterone-dependent PlGF expression leads to vascular injury, atherosclerosis, plaque formation and its inflammatory response $(10,11)$.

PlGF is considered to be crucial in pregnancy to initiate and perpetuate placental angiogenesis (reviewed in Zygmunt et al. Eur J Obstet Gynecol Reprod Biol 2003). As low levels compromise placental development, it also serves as early marker of pregnancies complicated by pre-eclampsia, a disease of placental origin $(12,13)$.

The role of environmental conditions on PlGF expression in pregnancy is less clear. Upregulation of angiogenic factors, such as PIGF, in trophoblast seems not to be supported by hypoxia and hypoxia-induced factor-1 $\alpha$ (14). As such, other regulatory pathways must be considered such as glucose availability, which might play a role in this process. While maternal serum levels of PIGF are high in diabetic pregnancies, similar to certain vascular beds such as in the retina, experimental evidence in diabetic rats suggests low PIGF levels in the placenta; thereby a differential regulation between systemic and placental PlGF in response to altered glucose availability (15-17).

Given the high systemic availability of aldosterone during pregnancy $(7,18)$, we hypothesized that aldosterone up-regulates growth-adaptive angiogenesis via placental PIGF expression. More specifically, we first aimed to identify trophoblast-derived aldosterone-sensitive PlGF expression; second to explore conditions most likely related to increased responsiveness such as starvation; and third, to investigate the relationship between aldosterone and PIGF in human pregnancy. 


\section{Methods}

\section{Patients}

A set of healthy pregnant women selected from the Bernese pregnancy registry at the Department of Obstetrics and Gynecology, University Hospital of Bern, with a complete scheduled sampling of serum and urine were included in the study. Clinical data were prospectively collected including obstetric parameters, ultrasound data, standardized measurement of office blood pressure and pregnancy outcome. Only normotensive, healthy pregnant women were included in the analysis. Visits were at gestation week $11 \pm 2,20 \pm 2$, $28 \pm 2$ and at birth. The study was approved by the ethics committee of the Canton of Bern and adheres to the principles of the Declaration of Helsinki. Study subjects were only included in the study after obtaining written informed consent.

A confirmatory patient set $(\mathrm{n}=36$ ) was derived from a prospective pregnancy cohort (number initially screened $n=3918$ ) at Maternity Units in Glasgow, UK. First trimester samples were taken at booking and those investigated who maintained normotensive throughout their pregnancy. The study was also approved by the West of Scotland Research ethics Committee and adheres to the principles of the Declaration of Helsinki. Study subjects were only included in the study after signing informed consent.

\section{Material and cell lines}

Collagen I-coated cell culture plates used for cell experiments were from Becton Dickinson (Basel, Switzerland). Cell culture media, L-glutamine, penicillin/streptomycin and HEPES were from Life Technologies, Inc./Invitrogen (Basel, Switzerland). Aldosterone was from Steraloids, Inc. (Brunschwig, Basel, Switzerland), forskolin, spironolactone, PlGF and fetal bovine serum (FBS) from Sigma (Buchs SG, Switzerland). Penicillin, streptomycin, and amphotericin B used for primary cell cultures were obtained from Invitrogen (Basel, Switzerland).

The human choriocarcinoma cell line BeWo and the adrenocortical carcinoma cell line NClH295R (H295R) were obtained from American Type Culture Collection (Manassas, VA). Human primary term trophoblasts were isolated from term placentas $(38-40 \mathrm{w})$ of healthy donors after obtaining informed consent from pregnant women at the Department of Obstetrics and Gynecology, University Hospital Bern, Switzerland. The isolation procedure was previously described (19). Primary cytotrophoblasts were resuspended in DMEM/F12K (1:1) containing 10\% FBS, penicillin, streptomycin, and amphotericin B and plated on collagen Icoated culture dishes. Cells were cultured at $37^{\circ} \mathrm{C}$ and $5 \% \mathrm{CO}_{2}$.

The human adrenal cell line H295R was cultured in DMEM-F12, $0.1 \%$ ITS+, and $5 \%$ NU-I. For the experiments, H295R cells were than incubated for $24 \mathrm{~h}$ in serum-free DMEM-F12 containing PBS, angiotensin II, PIGF or the combination of angiotensin II and PlGF. RNA was then extracted.

Human primary term trophoblasts and BeWo cells were cultured for $24 \mathrm{~h}$ in DMEM:F12K (1:1) medium with $10 \%$ FBS, then cells were washed with PBS, and fresh medium containing either $10 \%$ (for primary trophoblasts) or $0.1 \%$ (for BeWo) FBS supplemented with Aldo, forskolin or spironolactone for 6 or $24 \mathrm{~h}$. Following this incubation time, RNA was extracted from the cells and supernatant was taken for PIGF protein measurements.

\section{Real-time PCR}

Total RNA was extracted using Trizol reagent (Invitrogen, Basel, Switzerland). The RNA was then reverse transcribed (Prom II RT, Promega). For the real-time PCR, primers and probes for PlGF were obtained from Applied Biosystems (PIGF, Hs00182176_m1; CYP11B2, 
Hs01597732_m1; Applied Biosystems, Foster City, CA). GAPDH and cyclophilin A primers and probes (Applied Biosystems) served as independent endogenous controls. Real-time PCR reactions were performed using the Universal ProbeLibrary Assay probes and Taqman Fast Universal PCR Master Mix (Invitrogen, Basel, Switzerland). All data were normalised to cyclopholin A or GAPDH and presented as fold-change compared to the mean of the controls.

\section{PIGF ELISA}

BeWo and human primary term trophoblasts conditioned media were taken for PlGF protein measurement using a commercially available quantitative sandwich enzyme-linked immunosorbent assays (ELISA, R\&D Systems Europe Ltd., Abingdon, UK).

\section{Collection of urine and serum/plasma}

Morning urine samples were obtained from pregnant women in the longitudinal Bernese study and in the first trimester from the Glasgow cohort as has been described for population-based assessments (20). In all urine collections, creatinine concentrations were determined using routine methods. Serum and urine aliquots were stored at $-80^{\circ} \mathrm{C}$ until further analysis.

\section{Gas chromatography-mass spectrometry $(G C-M S)$}

Urinary tetrahydro-aldosterone (TH-aldosterone) was analyzed by GC-MS according to the method originally described by Shackleton and applied by us as reported earlier (7, 21). Briefly, urine preparation consisted of pre-extraction, enzymatic hydrolysis, extraction from the hydrolysis mixture, derivatization, and gel filtration. Medroxyprogesterone $(2.5 \mu \mathrm{g})$ was added as recovery standard to $1.5 \mathrm{ml}$ urine. Samples were extracted on a Sep Pak C18 column, dried, reconstituted in $0.1 \mathrm{M}$ acetate buffer ( $\mathrm{pH}$ 4.6) and hydrolyzed with powdered Helix pomatia enzyme $(12.5 \mathrm{mg})$ and $12.5 \mu \mathrm{l}$ of $\beta$-glucuronidase/arylsulfatase liquid enzyme at $55^{\circ} \mathrm{C}$ for $3 \mathrm{~h}$. The resulting free steroids were extracted on a Sep Pak C18 cartridge and $0.15 \mu \mathrm{g}$ of $3 \beta 5 \beta-\mathrm{TH}$-aldosterone was added as a standard for derivatization and chromatography. The samples were derivatized to form methyloxime-trimethylsilyl ethers. The derivatives were purified by gel filtration on Lipidex 5000 columns.

Samples were analyzed on a gas chromatograph $6890 \mathrm{~N}$ equipped with a mass selective detector 5973N (Agilent, La Jolla CA, USA) during a temperature-controlled run over $35 \mathrm{~min}$ by selected ion monitoring. One specific ion was monitored for each compound analyzed. A known amount of $3 \alpha 5 \beta$-TH-aldosterone was measured on a regular basis to act as a calibration standard. The recovery of the analysis was checked with medroxyprogesterone and results were corrected for the loss during sample preparation. The urinary concentration of $3 \alpha 5 \beta-\mathrm{TH}-$ aldosterone was normalized to urinary creatinine concentration.

\section{Statistical analysis}

All data in figures are presented as mean \pm SEM, whereas in text and tables mean \pm SD or mean $[95 \% \mathrm{CI}]$ are indicated. Data were tested for standard normal distribution using the Kolmogorov-Smirnov test before applying either unpaired student's t-test or nonparametric testing accordingly to analyze the difference observed between two groups. After testing for normal distribution, Pearson's correlation tests were used to correlate urinary TH-aldosterone concentrations to serum PlGF. Significance was assigned at $\mathrm{p}<0.05$. All statistical analyses were performed using GraphPad PRISM version 6 (PRISM,USA). 


\section{Results}

\section{Clinical data}

Demographic data of both the longitudinal Bernese and the complementary first trimester Glasgow cohort of healthy pregnant women with uneventful pregnancies and outcomes are shown in Table 1. The Glasgow cohort, though younger, is characterized by a higher risk profile including a higher BMI and blood pressure and characterized by earlier birth with lower birth weights.

\section{Association between urinary TH-aldosterone and serum PlGF levels}

Serum levels of PIGF rose, as expected, along gestation. In normotensive pregnancies, we identified a positive relationship between urinary TH-Aldo/creatinine levels and serum PlGF irrespective of gestational age (Figure $1 \mathrm{~A}, \mathrm{r}=0.3259, \mathrm{R}^{2}=0.1062 ; \mathrm{p}=0.001$ ). This strong correlation is maintained irrespective of limiting the analysis up to week 28 only, thus excluding birth data $\left(\mathrm{r}=0.2951, \mathrm{r}^{2}=0.0871, \mathrm{p}=0.0107\right)$. We further tested this association in normal pregnancy in a second cohort of first trimester pregnancy samples (Glasgow cohort) and the relationship was confirmed $\left(r=0.3581, \mathrm{R}^{2}=0.1282, \mathrm{p}=0.0295\right)$. Within pregnancy salt intake, which could potentially affect tetrahydroaldosterone excretion, as assessed by urinary $\mathrm{Na}^{+}$excretion was stable (Figure 1B). The expected rise in tetrahydroaldosterone excretion along gestation could be observed (Figure $1 \mathrm{C} ; \mathrm{p}<0.01$ ).

\section{Does PlGF stimulate adrenal aldosterone production?}

Upon stimulation of the human corticoadrenal carcinoma cell line H295R with PIGF (100 $\mathrm{ng} / \mathrm{ml}$ ), no augmentation of aldosterone synthase mRNA expression was observed, whereas angiotensin II $\left(10^{-7} \mathrm{M}\right)$ markedly amplified transcript availability (Figure 2, p<0.0001). Coincubation of PlGF and angiotensin II did not further raise aldosterone synthase expression, compared to angiotensin II alone (Figure 2).

\section{Aldosterone-dependent PlGF expression in human trophoblasts}

Incubation of the human trophoblast cell line, BeWo with different concentrations of aldosterone $\left(10^{-11}\right.$ to $\left.10^{-7} \mathrm{M}\right)$ did not increase PIGF expression. Upon challenging BeWo cells by adding forskolin $\left(2 \times 10^{-6} \mathrm{M}\right)$ to stimulate Protein Kinase A (PKA) and to induce syncytialization, we observed raised PlGF transcription ( $p<0.0001$ vs. control). Likewise, time-course experiments indicated a maximal stimulation by aldosterone already after $6 \mathrm{~h}$, an incubation period which was used in consecutive experiments. Upon co-incubation with forskolin for a time period of $6 \mathrm{~h}$, aldosterone enhanced PlGF expression with increasing effectiveness towards lower concentrations $\left(10^{-7}\right.$ to $10^{-11} \mathrm{M}$, ANOVA $\mathrm{p}=0.0011$; Figure $\left.3 \mathrm{~A}\right)$. Prolonged pre-incubation with forskolin for $48 \mathrm{~h}$ to induce syncytialization of BeWo cells reversed the dose relationship with aldosterone $\left(10^{-7}\right.$ to $10^{-11} \mathrm{M}, \mathrm{p}=0.0006$ [for aldosterone $10^{-7}$ $\mathrm{M}$ ] and $\mathrm{p}=0.0012$ [for aldosterone $10^{-9} \mathrm{M}$ ] vs. forskolin), added during the last $6 \mathrm{~h}$ (Figure 3B).

When spironolactone $\left(10^{-6} \mathrm{M}\right)$ was added to cultured human primary third trimester trophoblasts for $24 \mathrm{~h}$, a slight but consistent reduction of PIGF production was observed $(\mathrm{p}=0.026$; Figure $3 \mathrm{C})$, either unspecific or due to inhibiting the effect of mineralocorticoid active steroid hormones present in trophoblasts. Upon analysis of the baseline steroid hormone expression in trophoblasts, we could identify within the cells and in the supernatant a pattern compatible with intrinsic stimulatory mineralocorticoid-active steroid hormones, including the cortisol precursor 11-deoxycortisol and cortisol metabolites, but not corticosterone metabolites or aldosterone (Table 2). These findings were verified in cells cultured in the presence of charcoal-treated medium eliminating preformed steroid hormones. 
Addition of aldosterone $\left(10^{-7} \mathrm{M}\right)$ further $(\mathrm{p}=0.0175)$ enhanced forskolin-induced $\left(2 \times 10^{-6} \mathrm{M}\right.$, $\mathrm{p}=0.025)$ PlGF transcription, which could be completely reversed by the addition of spironolactone ( $\mathrm{p}=0.024$; Figure $3 \mathrm{C}$ ). The PlGF protein expression as measured in primary human trophoblasts paralleled these observations (data not shown).

A mild but consistent inhibitory impact of incubation with cortisol on PlGF production suggested no unspecific stimulation of the mineralocorticoid receptor by cortisol in conditions of unaffected $11 \beta$-hydroxysteroid dehydrogenase activity type 2 , an entity reported earlier by our group and others (data not shown) $(22,23)$.

\section{PlGF expression simulated by low glucose incubation}

To study whether insufficient nutrient availability triggers or enhances angiogenic signals such as PlGF, we exposed BeWo cells to low glucose concentrations (3.5 vs. $16 \mathrm{mmol} / \mathrm{l})$. In these cells, the forskolin-stimulated increase in PIGF expression ( $\mathrm{p}=0.0035$ vs. control; Figure 4) disclosed in our baseline glucose concentration, was further enhanced in low glucose conditions ( $\mathrm{p}<0.0001$ vs. normal glucose). Incubation with aldosterone $\left(10^{-7} \mathrm{M}\right)$ alone did not affect PIGF expression, irrespective of the glucose concentration. Upon co-incubation of forskolin $\left(2 \times 10^{-6} \mathrm{M}\right)$ and aldosterone we observed a 3 -fold stimulation of PIGF expression in normal $(\mathrm{p}=0.0319)$ and a more than 10-fold enhanced expression in low glucose concentrations $(\mathrm{p}<0.0001)$. Accordingly, co-incubation of both aldosterone and forskolin in low glucose conditions was strikingly more intense then in normal glucose conditions $(\mathrm{p}<0.0001 ;$ Figure 4). 


\section{Discussion}

Limited data in clinical conditions outside pregnancy suggest a role for aldosterone in upregulating PIGF. PIGF is a clinical useful marker of placental angiogenic properties in pregnancy. Given the placental growth properties of aldosterone in pregnancy, such a feature might be of importance for adaptive angiogenesis.

This study demonstrates that in normal human pregnancy, circulating PlGF levels are closely linked to aldosterone availability throughout pregnancy. Obviously, the aldosterone-dependent PlGF stimulation is not challenged in the first trimester in pregnancy. Earlier studies suggest an insufficient aldosterone response in the high aldosterone pregnancy state, either genetically or due to modifying factors $(3,9)$.

Given the known stimulatory effect of angiotensin II and the angiogenic VEGF on adrenal aldosterone production (9), the VEGF homologue PIGF is also a likely candidate. Conversely, VEGF-receptor type 1, the target of PIGF is not expressed on adrenal epithelial cells, suggesting the absence of any PIGF effect. As expected, PIGF did not stimulate aldosterone production in vitro in adrenal cells, known to produce aldosterone via CYP11B2, whereas on the contrary, we could clearly show that given certain prerequisites, aldosterone stimulates PIGF expression. PKA activation, as stimulated by the addition of forskolin and supporting syncytialization was critically required. Addition of aldosterone enhanced PIGF expression, which was further amplified in conditions of low glucose, simulating starvation. These observations are in agreement with the assumption of an enhanced angiogenesis upon starving trophoblasts. Moreover, they bridge environmental conditions and local regulation to an overall placental response.

Additionally, our findings are in line with observations in animal models of atherosclerosis and vascular damage, where aldosterone increased aortic PIGF expression, but also in nonaged mouse aorta $(10,11,24)$. While the former two models suggest a strong PlGF stimulation upon aldosterone in conditions of local oxidative stress and compromised blood supply, the latter also identified aldosterone-stimulated PIGF expression in non-compromised vessels.

The systemic response in humans to diabetic conditions, suggests an enhanced PlGF production, which has been observed in certain microvascular areas. However, PlGF production is reduced within the placenta in experimental hyperglycemic rats (15-17). In contrast, low glucose or fasting conditions are known to induce hepatic gluconeogenesis in a cAMP/PKA/CREB-dependent manner (25). This pathway has been shown to activate the PlGF gene promoter explaining the response observed with low glucose concentrations in our experiments (26).

The results from the current study could explain an effective coordinated action of aldosterone on placental growth and adaptive angiogenesis. Nevertheless, we cannot extrapolate from our data whether the PIGF systemically found during pregnancy is purely of placental origin, given the huge endothelial and vascular smooth muscle cell mass in the systemic maternal circulation. Very carefully obtained data from placental vessels have suggested a major placental source of PIGF, as the placental PIGF arterial inflow was low, whereas the outflow was high (27). This report does not preclude a local vascular PIGF production, potentially providing significant cellular auto- or paracrine humeral adaptations.

The strength of our current investigation is the combination of independent clinical cohorts with additional isolated primary term human trophoblast cell culture in vitro. In addition, application of different cell culture systems, beyond the rather artificial model, given by the choriocarcinoma BeWo cell lines, by use of carefully isolated and thoroughly characterized primary term human trophoblasts adds further merit (28). A few limitations exist; first, although placental growth is significant in the second trimester, isolated human primary trophoblasts were not available within this time frame without further comorbid conditions 
precluding their use. Second, systemic PlGF is only a surrogate of the actual placental production of PIGF, though obviously closely related to urinary aldosterone.

In conclusion, we have demonstrated that by stimulating placental PIGF production, aldosterone has additional effects in pregnancy beyond trophoblast growth promotion and optimizing fetal hemodynamics. The close relationship with conditions of starvation, suggests that this could be a local trigger occurring upon aldosterone-stimulated trophoblast proliferation in less well vascularized areas, as summarized and depicted in Figure 5. An impact of alternative mineralocorticoid active steroid hormones is likely, yet not major.

Cortisol has a minor inhibitory function in this process, which might be overwhelming in conditions of established pre-eclampsia, with compromised intracellular cortisol degradation by the enzyme $11 \beta$-hydroxysteroid dehydrogenase type 2 , as has been previously reported ( 29 , 30). Inappropriate aldosterone availability could thus be of clinical interest and supplementation by artificial mineralocorticoid agonistic drugs, such as fludrocortisone might enhance PIGF in conditions of critically low availability. Further studies are definitely warranted to further explore these issues.

\section{Author Contribution}

NE, CA, BD, GC, and CG-M performed the research; NE, HDM, MGM and CG-M analysed the data. All authors wrote, revised and approved the manuscript.

\section{Acknowledgements}

We are deeply indebted to all pregnant women and their families for participation. We acknowledge the excellent technical support of Heidi Jamin.

\section{Funding}

This research was supported by the Swiss National Foundation (personal grant 32-135596 to MGM and 310030_149958 to CA) and the Swiss National Center of Competence in Research, NCCR TransCure (CA). HDM is supported by an ERA-EDTA Fellowship (LTF 137-2013). $\mathrm{CD}$ is supported by grants from the European Union (EU-MASCARA; project reference 278249) and the Chief Scientist Office (reference ETM/196). Additional complementary support by the clinical research fund of the Department of Obstetrics and Gynecology, University Hospital Bern, Switzerland. 


\section{References}

1 Luft F. C., Gallery E. D. M., Lindheimer M. D. Normal and abnormal volume homeostasis. 3rd ed. Amsterdam: Elsevier; 2009. 269-285 p.

2 Hytten F. E. Weight gain in pregnancy. In: Hytten FE, Chamberlain G, editors. Clinical Physiology in Obstetrics. Oxford: Blackwell Scientific; 1980: p. 193-233.

3 Escher G., Cristiano M., Causevic M., Baumann M., Frey F. J., Surbek D., Mohaupt M. G. (2009) High aldosterone-to-renin variants of CYP11B2 and pregnancy outcome. Nephrol Dial Transplant 24, 1870-1875

4 Jensen E., Wood C. E., Keller-Wood M. (2005) Chronic alterations in ovine maternal corticosteroid levels influence uterine blood flow and placental and fetal growth. Am J Physiol Regul Integr Comp Physiol 288, R54-61

5 Gennari-Moser C., Khankin E. V., Schuller S., Escher G., Frey B. M., Portmann C. B., Baumann M. U., Lehmann A. D., Surbek D., Karumanchi S. A. et al. (2011) Regulation of placental growth by aldosterone and cortisol. Endocrinology 152, 263-271

6 Todkar A., Di Chiara M., Loffing-Cueni D., Bettoni C., Mohaupt M., Loffing J., Wagner C. A. (2012) Aldosterone deficiency adversely affects pregnancy outcome in mice. Pflugers Arch 464, 331-343

7 Shojaati K., Causevic M., Kadereit B., Dick B., Imobersteg J., Schneider H., Beinder E., Kashiwagi M., Frey B. M., Frey F. J. et al. (2004) Evidence for compromised aldosterone synthase enzyme activity in preeclampsia. Kidney Int 66, 2322-2328

8 Farese S., Shojaati K., Kadereit B., Frey F. J., Mohaupt M. G. (2006) Blood pressure reduction in pregnancy by sodium chloride. Nephrol Dial Transplant 21, 1984-1987

9 Gennari-Moser C., Khankin E. V., Escher G., Burkhard F., Frey B. M., Karumanchi S. A., Frey F. J., Mohaupt M. G. (2013) Vascular Endothelial Growth Factor-A and Aldosterone: Relevance to Normal Pregnancy and Preeclampsia. Hypertension, 1111-1117

10 McGraw A. P., Bagley J., Chen W. S., Galayda C., Nickerson H., Armani A., Caprio M., Carmeliet P., Jaffe I. Z. (2013) Aldosterone increases early atherosclerosis and promotes plaque inflammation through a placental growth factor-dependent mechanism. Journal of the American Heart Association 2, e000018

11 Jaffe I. Z., Newfell B. G., Aronovitz M., Mohammad N. N., McGraw A. P., Perreault R. E., Carmeliet P., Ehsan A., Mendelsohn M. E. (2010) Placental growth factor mediates aldosterone-dependent vascular injury in mice. J Clin Invest 120, 3891-3900

12 Baumann M. U., Bersinger N. A., Surbek D. V. (2007) Serum markers for predicting pre-eclampsia. Mol Aspects Med 28, 227-244

13 Baumann M. U., Bersinger N. A., Mohaupt M. G., Raio L., Gerber S., Surbek D. V. (2008) First-trimester serum levels of soluble endoglin and soluble fms-like tyrosine kinase-1 as first-trimester markers for late-onset preeclampsia. Am J Obstet Gynecol 199, 266 e261266

14 Gobble R. M., Groesch K. A., Chang M., Torry R. J., Torry D. S. (2009) Differential regulation of human PIGF gene expression in trophoblast and nontrophoblast cells by oxygen tension. Placenta 30, 869-875

15 Koh P. O., Sung J. H., Won C. K., Cho J. H., Moon J. G., Park O. S., Kim M. O. (2007) Streptozotocin-induced diabetes decreases placenta growth factor (PIGF) levels in rat placenta. The Journal of veterinary medical science / the Japanese Society of Veterinary Science 69, 877-880

16 Zhao B., Cai J., Boulton M. (2004) Expression of placenta growth factor is regulated by both VEGF and hyperglycaemia via VEGFR-2. Microvasc Res 68, 239-246

17 Ong C. Y., Lao T. T., Spencer K., Nicolaides K. H. (2004) Maternal serum level of placental growth factor in diabetic pregnancies. The Journal of reproductive medicine 49, 477-480 
18 Brown M. A., Gallery E. D. (1994) Volume homeostasis in normal pregnancy and preeclampsia: physiology and clinical implications. Baillieres Clin Obstet Gynaecol 8, 287-310

19 Nikitina L., Wenger F., Baumann M., Surbek D., Korner M., Albrecht C. (2011) Expression and localization pattern of ABCA1 in diverse human placental primary cells and tissues. Placenta 32, 420-430

20 O'Donnell M. J., Yusuf S., Mente A., Gao P., Mann J. F., Teo K., McQueen M., Sleight P., Sharma A. M., Dans A. et al. (2011) Urinary sodium and potassium excretion and risk of cardiovascular events. Jama 306, 2229-2238

21 Shackleton C. H. (1993) Mass spectrometry in the diagnosis of steroid-related disorders and in hypertension research. J Steroid Biochem Mol Biol 45, 127-140

22 Stewart P. M., Rogerson F. M., Mason J. I. (1995) Type 2 11ß-hydroxysteroid dehydrogenase messenger ribonucleic acid and activity in human placenta and fetal membranes: its relationship to birth weight and putative role in fetal adrenal steroidogenesis. J Clin Endocrinol Metab 80, 885-890

23 Lanz B., Kadereit B., Ernst S., Shojaati K., Causevic M., Frey B. M., Frey F. J., Mohaupt M. G. (2003) Angiotensin II regulates 11ß-hydroxysteroid dehydrogenase type 2 via AT2 receptors. Kidney Int 64, 970-977

24 Pruthi D., McCurley A., Aronovitz M., Galayda C., Karumanchi S. A., Jaffe I. Z. (2014) Aldosterone promotes vascular remodeling by direct effects on smooth muscle cell mineralocorticoid receptors. Arterioscler Thromb Vasc Biol 34, 355-364

25 Wang T., Xu J., Bo T., Zhou X., Jiang X., Gao L., Zhao J. (2013) Decreased fasting blood glucose is associated with impaired hepatic glucose production in thyroid-stimulating hormone receptor knockout mice. Endocrine journal 60, 941-950

26 Depoix C., Tee M. K., Taylor R. N. (2011) Molecular regulation of human placental growth factor (PIGF) gene expression in placental villi and trophoblast cells is mediated via the protein kinase a pathway. Reprod Sci 18, 219-228

27 Bujold E., Romero R., Chaiworapongsa T., Kim Y. M., Kim G. J., Kim M. R., Espinoza J., Goncalves L. F., Edwin S., Mazor M. (2005) Evidence supporting that the excess of the sVEGFR-1 concentration in maternal plasma in preeclampsia has a uterine origin. J Matern Fetal Neonatal Med 18, 9-16

28 Baumann M., Korner M., Huang X., Wenger F., Surbek D., Albrecht C. (2013) Placental ABCA1 and ABCG1 expression in gestational disease: Pre-eclampsia affects ABCA1 levels in syncytiotrophoblasts. Placenta 34, 1079-1086

29 Walker B. R., Williamson P. M., Brown M. A., Honour J. W., Edwards C. R., Whitworth J. A. (1995) 11ß-Hydroxysteroid dehydrogenase and its inhibitors in hypertensive pregnancy. Hypertension 25, 626-630

30 Schoof E., Girstl M., Frobenius W., Kirschbaum M., Dorr H. G., Rascher W., Dotsch J. (2001) Decreased gene expression of 11ß-hydroxysteroid dehydrogenase type 2 and 15hydroxyprostaglandin dehydrogenase in human placenta of patients with preeclampsia. J Clin Endocrinol Metab 86, 1313-1317 


\section{Figure legends}

\section{Figure 1}

A) Association between urinary tetrahydroaldosterone concentration corrected for creatinine and serum placental growth factor (PIGF) levels in healthy pregnancy across gestation (first cohort). A positive correlation was observed $\left(r=0.2951, \mathrm{R}^{2}=0.0871 ; \mathrm{p}=0.0107 ; \mathrm{n}=24\right.$ individual women).

B) Salt intake indicated as urinary $\mathrm{Na}^{+} /$creatinine remained stable throughout the indicated gestational ages ( $\mathrm{n}=24$ individual women).

C) The gestational rise in aldosterone availability was assessed as urinary tetrahydroaldosterone excretion corrected for urinary creatinine ( $\mathrm{n}=24$ individual women); $* * \mathrm{p}<0.01$.

\section{Figure 2}

Aldosterone synthase (CYP11B2) expression, following incubation with angiotensin II (Ang II) and/or placental growth factor (PIGF). PlGF does not stimulate adrenal CYP11B2 expression. Upon stimulation of the human corticoadrenal cell line H295R with PIGF (100 $\mathrm{ng} / \mathrm{ml})$ and with Ang II $\left(10^{-7} \mathrm{M}\right)$ alone, or in combination for $24 \mathrm{~h}$, PlGF did not contribute to a stimulated CYP11B2 transcript expression as measured by TaqMan PCR corrected for cyclophilin A. Mean \pm SEM is given $(n=3) ; * * * p<0.0001$.

\section{Figure 3}

Aldosterone-dependent augmentation of forskolin-induced PIGF transcription in the BeWo cell line and cultured primary third trimester human trophoblasts.

A) Short time exposure with forskolin $\left(2 \times 10^{-6} \mathrm{M}\right)$ for $6 \mathrm{~h}$ sensitized cultured BeWo cells to enhanced PlGF transcription in the simultaneous presence of minor concentrations of aldosterone. Depicted is a representative experiment (mean \pm SEM, $n=3$ ); **p=0.0011 ANOVA of forskolin-treated experiments.

B) If the pre-exposure of cultured BeWo cells to forskolin was extended to $48 \mathrm{~h}$, higher concentrations of aldosterone for $6 \mathrm{~h}$ were required for the PIGF augmentation. Mean $\pm \mathrm{SEM}$, $\mathrm{n}=3) ; * * * \mathrm{p}<0.001$.

C) In cultured human primary trophoblasts $24 \mathrm{~h}$ incubation with spironolactone $\left(10^{-6} \mathrm{M}\right)$ slightly but consistently reduced PIGF expression. Addition of aldosterone $\left(10^{-7} \mathrm{M}\right)$ further enhanced forskolin-induced $\left(2 \times 10^{-6} \mathrm{M}\right)$ PlGF transcription, which could be completely reversed by the addition of spironolactone. Mean \pm SEM are given $(n=3-6) ; * p<0.05$.

\section{Figure 4}

Effect of starvation on the BeWo cell line, simulated by low glucose exposure in the incubation medium on PIGF expression. In normal glucose conditions (black bars) forskolin (2 x $\left.10^{-6} \mathrm{M}\right)$ stimulated PIGF expression further enhanced by aldosterone $\left(10^{-7} \mathrm{M}\right)$. Reducing glucose availability (white bars) led to a marked increase in PIGF transcription irrespective of incubation with forskolin alone or if forskolin was combined with aldosterone. Mean \pm SEM are given, $\mathrm{n}=4-10 ; * \mathrm{p}<0.05, * * \mathrm{p}<0.01, * * * \mathrm{p}<0.001$.

\section{Figure 5}

Scheme indicating the proposed regulation of placental angiogenic adaptation in normal and environmental challenging conditions, favoring high aldosterone levels and leading to starvation. This will contribute to local starvation due to increased proliferation and insufficient angiogenesis. The presence of PKA activation and aldosterone, enhance PlGF production and thus support angiogenesis. Similarly, systemic starvation and reduced maternal access to salt and water will in turn drive aldosterone synthesis, subsequently accentuating 
PlGF expression. High local PIGF levels will then support placental angiogenesis and systemic maternal endothelial adaptation and an appropriate pregnancy outcome. 
Table 1

Details of primiparous pregnant women; data show as mean $\pm \mathrm{SD}$.

\begin{tabular}{|c|c|c|c|c|c|c|}
\hline Main demographic data & \multicolumn{2}{|c|}{ Berne cohort } & \multicolumn{3}{|c|}{ Glasgow cohort } & $\mathbf{p}$ \\
\hline Patients [n] & \multicolumn{2}{|l|}{26} & \multicolumn{3}{|l|}{36} & \\
\hline Age [y] & 31.5 & 0.8 & 29.5 & \pm & 1.0 & $<0.0001$ \\
\hline Gestational age at birth [w] & 39.8 & 0.3 & 39.3 & \pm & 0.6 & 0.0002 \\
\hline Neonatal weight [g] & 3481 & \pm 110 & 3345 & \pm & 145 & 0.0002 \\
\hline \multicolumn{7}{|l|}{ Office blood pressure at booking } \\
\hline systolic $[\mathrm{mmHg}]$ & 113 & \pm & 115 & \pm & 2 & 0.0003 \\
\hline diastolic $[\mathrm{mmHg}]$ & 67 & \pm & 70 & \pm & 2 & $<0.0001$ \\
\hline BMI before pregnancy $\left[\mathrm{kg} / \mathrm{m}^{2}\right]$ & 21.4 & 0.7 & 27.2 & \pm & 1.0 & $<0.0001$ \\
\hline
\end{tabular}


Table 2

Steroid hormone metabolites in cultured BeWo cells

Steroid hormone metabolites

Expressed in BeWo cells cultured in

\begin{tabular}{|c|c|c|c|c|}
\hline & \multicolumn{2}{|c|}{ Regular medium } & \multicolumn{2}{|c|}{$\begin{array}{c}\text { Charcoal-treated } \\
\text { medium }\end{array}$} \\
\hline & $\mathbf{0 ~ h}$ & $24 \mathrm{~h}$ & $\mathbf{0 ~ h}$ & $24 \mathrm{~h}$ \\
\hline \multicolumn{5}{|l|}{ Androgens } \\
\hline Androsterone & $\mathrm{x}$ & $\mathrm{x}$ & $\mathrm{x}$ & $\mathrm{x}$ \\
\hline $\begin{array}{l}\text { Etiocholanolone } \\
\text { Androstenediol } \\
\text { 11-Oxo-Etiocholanolon }\end{array}$ & $\mathrm{x}$ & $\mathrm{x}$ & $\mathrm{x}$ & $\mathrm{x}$ \\
\hline $11 \beta$-Hydroxyandrosterone & $\mathrm{x}$ & $\mathrm{x}$ & $\mathrm{x}$ & $\mathrm{x}$ \\
\hline $11 \beta$-Hydroxyetiocholanolone & $\mathrm{x}$ & $\mathrm{x}$ & $\mathrm{x}$ & $\mathrm{x}$ \\
\hline $\begin{array}{l}\text { Dehydroepiandrosterone } \\
\text { 5-Androstene- } 3 \beta, 17 \beta \text {-diol }\end{array}$ & & $\mathrm{x}$ & & $\mathrm{x}$ \\
\hline 16a-Hydroxy-DHEA & & $\mathrm{x}$ & & $\mathrm{x}$ \\
\hline 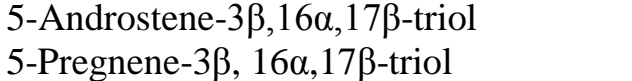 & $\mathrm{x}$ & $\mathrm{x}$ & $\mathrm{x}$ & $\mathrm{x}$ \\
\hline Testosterone & & & & \\
\hline $5 \alpha$-Dihydrotestosterone & & & & \\
\hline \multicolumn{5}{|l|}{ Estrogens } \\
\hline Estriol & $\mathrm{x}$ & $\mathrm{x}$ & $\mathrm{x}$ & $\mathrm{x}$ \\
\hline $17 \beta$-Estradiol & $\mathrm{x}$ & $\mathrm{x}$ & $\mathrm{x}$ & $\mathrm{x}$ \\
\hline \multicolumn{5}{|l|}{ Progesterons } \\
\hline \multicolumn{5}{|l|}{ 17-Hydroxypregnanolon } \\
\hline \multicolumn{5}{|l|}{ Pregnanediol } \\
\hline Pregnanetriol & $\mathrm{x}$ & $\mathrm{x}$ & $\mathrm{x}$ & $\mathrm{x}$ \\
\hline 11-Oxopregnanetriol & $\mathrm{x}$ & $\mathrm{x}$ & $\mathrm{x}$ & $\mathrm{x}$ \\
\hline \multicolumn{5}{|l|}{ 11-Deoxycortisol } \\
\hline Tetrahydro-11-deoxycortisol & $\mathrm{x}$ & $\mathrm{x}$ & $\mathrm{x}$ & $\mathrm{x}$ \\
\hline \multicolumn{5}{|l|}{ Aldosterone } \\
\hline \multicolumn{5}{|l|}{ Tetrahydroaldosterone } \\
\hline \multicolumn{5}{|l|}{ Corticosterones } \\
\hline \multicolumn{5}{|l|}{ Deoxycorticosterone } \\
\hline \multicolumn{5}{|l|}{ Tetrahydrodeoxycorticosterone } \\
\hline \multicolumn{5}{|l|}{ Tetrahydrodihydrocorticosterone } \\
\hline \multicolumn{5}{|l|}{ Tetrahydrocorticosterone } \\
\hline \multicolumn{5}{|l|}{$5 \alpha$-Tetrahydrocorticosterone } \\
\hline \multicolumn{5}{|l|}{ 18-OH-tetrahydrodihydrocorticosterone } \\
\hline \multicolumn{5}{|l|}{ Cortisols } \\
\hline \multicolumn{5}{|l|}{ Cortisone } \\
\hline Tetrahydrocortisone & $\mathrm{x}$ & $\mathrm{x}$ & $\mathrm{x}$ & $\mathrm{x}$ \\
\hline$\alpha / \beta$-Cortolone & $\mathrm{x}$ & $\mathrm{x}$ & $\mathrm{x}$ & $\mathrm{x}$ \\
\hline \multicolumn{5}{|l|}{$20 \alpha / \beta$-Dihydrocortison } \\
\hline \multicolumn{5}{|l|}{ Cortisol } \\
\hline Tetrahydrocortisol & $\mathrm{x}$ & $\mathrm{x}$ & $\mathrm{x}$ & $\mathrm{x}$ \\
\hline $\begin{array}{l}5 \alpha \text {-Tetrahydrocortisol } \\
\alpha \text {-Cortol }\end{array}$ & $\mathrm{x}$ & $\mathrm{x}$ & $\mathrm{x}$ & $\mathrm{x}$ \\
\hline$\beta$-Cortol & $\mathrm{x}$ & $\mathrm{x}$ & $\mathrm{x}$ & $\mathrm{x}$ \\
\hline $20 \alpha / \beta$-Dihydrocortisol & & & & \\
\hline 6 $\beta / 18$-Hydroxycortisol & & & & \\
\hline
\end{tabular}

